\title{
Reduction of Iron(III) lons at Elevated Pressure by Acidophilic Microorganisms
}

\author{
Ruiyong Zhang ${ }^{a^{*}}$, Sabrina Hedrich ${ }^{b}$ and Axel Schippers ${ }^{c}$ \\ Federal Institute for Geosciences and Natural Resources (BGR), Hannover, Germany \\ aruiyong.zhang@bgr.de, bsabrina.hedrich@bgr.de, caxel.schippers@bgr.de
}

Keywords: acidophiles, high pressure, ferric reduction, sulfur oxidation, in situ bioleaching

\begin{abstract}
A composed mixed acidophilic, iron-oxidizing culture (FIGB) and a thermo-acidophilic enrichment culture (TK65) were used to evaluate microbial iron(III) reduction coupled to oxidation of reduced inorganic sulfur compounds (RISCs) under high pressure. Experiments were done in batch culture in high pressure vessels at 1 and 100 bar. Microbial abundance and activity were determined by measuring iron(II) concentration, direct cell counting, T-RFLP and quantitative realtime PCR. The data indicate that both cultures are able to reduce soluble iron(III) by oxidation of sulfur compounds under anaerobic conditions. At high pressure (100 bar) these acidophiles were capable of growing and microbial ferric iron reduction was only partially inhibited. These results indicate that acidophiles can be barotolerant and their activities are contributing to sulfur and iron cycling in anaerobic environments including deep ore deposits which is highly relevant for in situ leaching operations.
\end{abstract}

\section{Introduction}

The verified microbial leaching mechanism (indirect mechanism) relies on the main oxidant iron(III) ions which causes metal sulfide (MS) dissolution. Acidophilic microorganisms contribute to MS dissolution by providing iron(III) ions and/or protons because of their iron/sulfur oxidation activities in the presence of oxygen [1]. In some leaching environments such as heap leaching or large-scale in situ leaching operations the concentration of dissolved ferric iron may be several orders of magnitude greater than that of molecular oxygen. The relevance of microbial iron(III) reduction for the leaching of MS and the generation of acid mine/rock drainage (AMD/ARD) is of considerable interest.

The EU Horizon 2020 project BIOMOre aims to develop a new mining technique for extracting metals from deep $(>1 \mathrm{~km})$ ore deposits using biotechnology [2, 3]. The anaerobic microbial oxidation of reduced inorganic sulfur compounds (RISCs) using iron(III) as electron acceptor is likely the most important sub-surface microbial process involved in in situ leaching of the ore deposit where elevated temperature and pressure occur. Hydrostatic pressure has hardly been considered as an environmental factor in bioleaching to date. In this study, we focused on the evaluation of anaerobic iron(III) reduction coupled to sulfur oxidation in presence of Polish Kupferschiefer-associated sandstone $(\mathrm{SS})$ ore $(\mathrm{Cu} 2.48 \%, \mathrm{Fe} 0.44 \%, \mathrm{~S} 0.14 \%)$ by acidophilic bacteria and archaea at elevated temperatures and high hydrostatic pressure (100 bar). The mixed culture FIGB and a thermophilic enrichment culture from sandstone/blackshale materials were chosen as test organisms.

\section{Materials and Methods}

Culture and medium. The composed mixed acidophilic, iron-oxidizing culture FIGB [3] was kindly provided by Barrie Johnson (Bangor, UK). The TK65 culture was enriched from black shale/sandstone (Rudna-Mine ore, Poland) and was identified as a mixed culture of Acidianus (A.) brierleyi, Thermoplasma (T.) acidophilum and Sulfolobus metallicus by $16 \mathrm{~S}$ rRNA gene cloning and sequencing. Both cultures were cultivated in autotrophic basal salts medium [4]. The FIGB culture was maintained aerobically in a liquid medium containing $50 \mathrm{mM}$ iron(II) ions. The TK65 
culture was anaerobically cultivated with $50 \mathrm{mM}$ iron(III) ions, $10 \mathrm{~g} / \mathrm{L}$ elemental sulfur, $10 \mathrm{~g} / \mathrm{L}$ black shale or Kupferschiefer-associated sandstone (KGHM Poland) and 0.04\% yeast extract at $60{ }^{\circ} \mathrm{C}$.

Pressure vessel experiments. Batch experiments were performed to study the microbial activity at 100 bar under anoxic conditions. The FIGB culture was cultivated in basal salts medium with $50 \mathrm{mM}$ iron(III) ions and $10 \%$ elemental sulfur or $5 \mathrm{mM}$ potassium tetrathionate (PT), or $5 \mathrm{mM}$ PT plus $10 \%$ SS. For TK65, $0.04 \%$ yeast extract was added to the culture medium. To achieve a pressure of 100 bar, a high-pressure incubation system was used (Fig. 1). Briefly, $10 \mathrm{~mL}$ of culture with different substrates were loaded in Hungate glass tubes $(20 \mathrm{~mL}$; Fig. 1b). The tubes were sealed with rubber stoppers and secured with aluminum caps to assure anoxic conditions. Afterwards, $1 \mathrm{~mL}$ of $\mathrm{CO}_{2}$ was injected into the tubes after flushing with nitrogen for $30 \mathrm{~min}$. These tubes connected with hypodermic needles with sterile syringes $(10 \mathrm{~mL})$ which were filled with medium were placed in a high-pressure vessel. The syringe itself was used to transmit the external hydrostatic pressure into the culture in the tubes as described elsewhere [5].

(a)

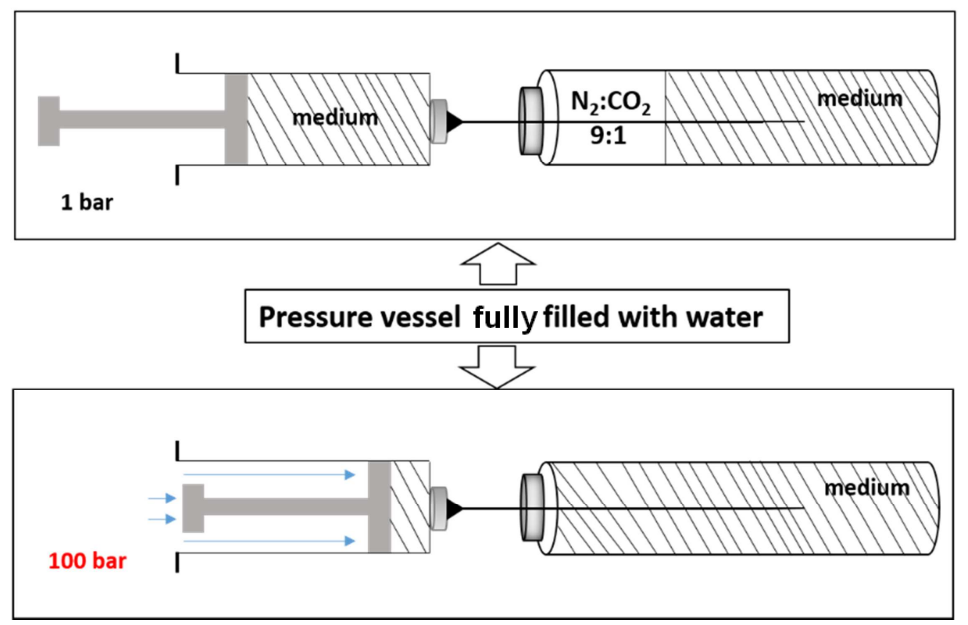

(b)

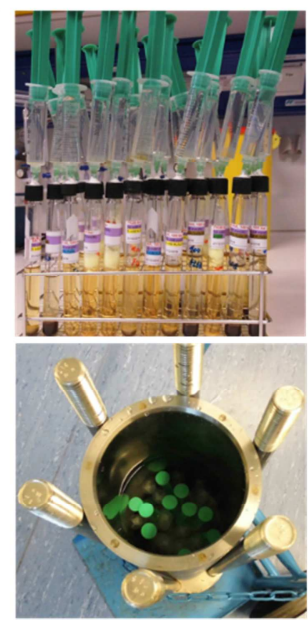

(c)

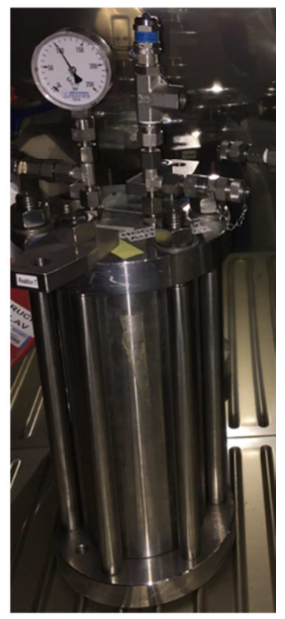

Fig. 1. High pressure generation system used in this study. (a) Schematic of the high-pressure incubation chamber; (b) upper: Batch of cultures inoculated in Hungate tubes connected with hypodermic needles with sterile syringes, lower: tubes immersed into water in a high pressure vessel; (c) High pressure vessel operated at 100 bar in an incubator.

Cell enumeration and iron determination. Iron(II) ion concentration was determined according to the ferrozine assay [6]. Planktonic cells were counted directly by using a light microscope (Leica DM3000) with a Thoma Chamber (Hecht-Assistent).

T-RFLP and quantitative real time-PCR. DNA isolation and T-RFLP analysis were carried out as described previously [7, 8]. Copy numbers of bacterial and archaeal 16S rRNA genes were determined by quantitative real-time PCR (qPCR) using universal bacterial- and archaeal-specific primers as described previously $[9,10]$.

\section{Results and Discussion}

Fig. 2 shows the planktonic cell numbers, community composition and iron(III) reduction by the FIGB culture after 1 week incubation at $30{ }^{\circ} \mathrm{C}$ at 1 bar (atmospheric pressure) or 100 bar. It is obvious that cells readily grew on different substrates at 1 bar. A significant $\mathrm{pH}$ drop from 1.8 to $\sim 1.2$ indicated oxidation of sulfur compounds to sulfuric acid in all the tested assays (data not shown). As indicated by both, 16S rRNA gene copy number and direct cell count, cell density was highest when grown on $5 \mathrm{mM}$ potassium tetrathionate (PT; Fig. 2a and b). In presence of SS the planktonic cell numbers were considerably lower, likely due to cell attachment. The cell numbers in the assays with elemental sulfur or PT plus SS were similar. Iron reduction was comparable for 
cells grown on all three substrates (elemental sulfur, PT and PT+SS), with 33-37 mM iron(II) generated after 1 week incubation. For assays at 100 bar, significant cell growth was observed too. However, all cell and gene copy numbers were lower than for the respective 1 bar experiments reflecting a partial inhibition of growth for all three substrates. This inhibition was up to $38 \%$ for cells grown on $\mathrm{PT}+\mathrm{SS}$ at 100 bar compared to those at 1 bar, considering both, gene copy number and direct cell count. Consistent with the reduced cell numbers at 100 bar, iron(III) reduction was reduced by $50.3 \%$ if compared to the one-bar assays.

(a)

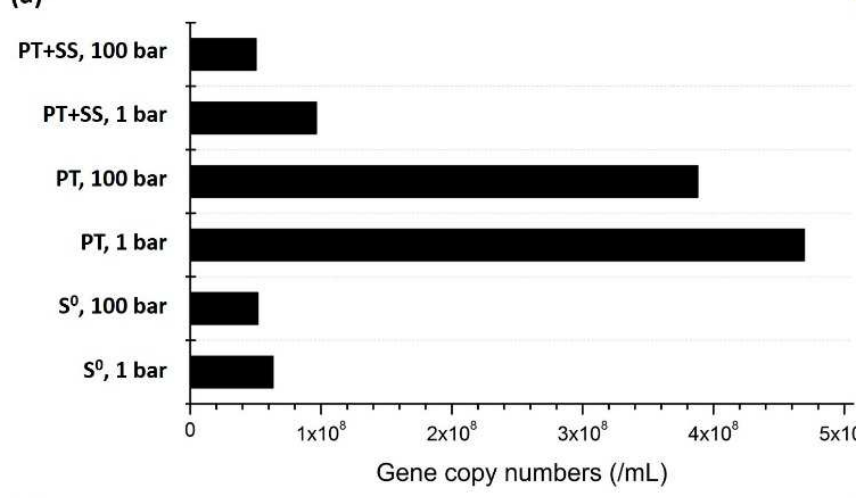

(c)

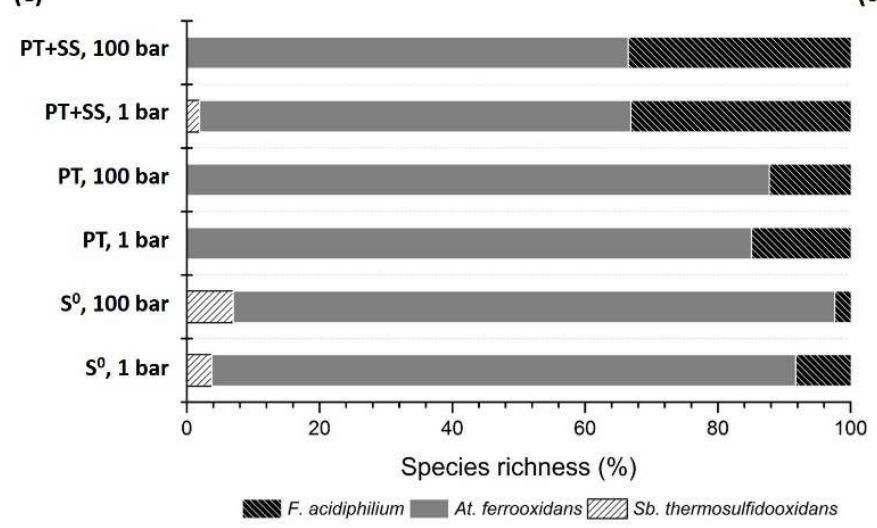

(b)

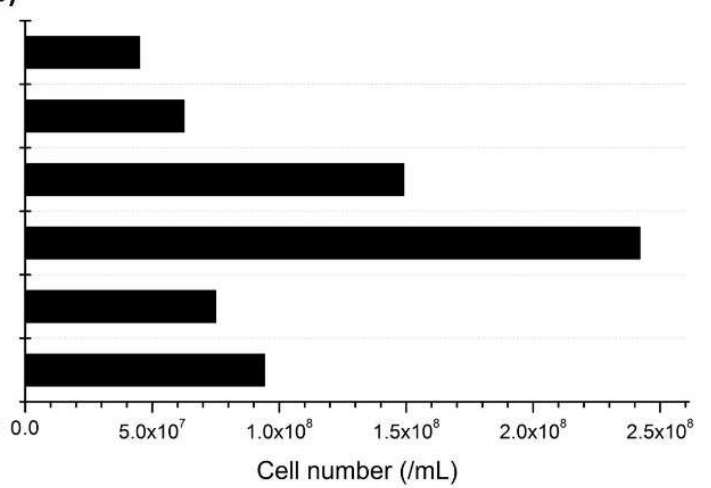

(d)

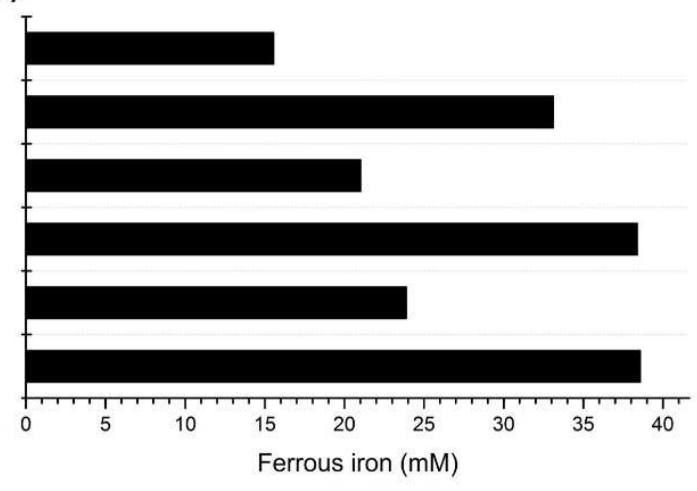

Fig. 2. Pressure effect on growth and iron(III) reduction by the FIGB culture. (a) Sum of archaeal and bacterial 16S rRNA gene copy numbers determined by qPCR; (b) cell numbers by direct microscopic counting; (c) microbial community analysis by T-RFLP; (d) iron(II) concentration due to iron(III) reduction. In all assays the initial cell number was $\sim 10^{7}$ cells/ $\mathrm{mL}$. Experiments were run in Hungates tubes anaerobically at $30{ }^{\circ} \mathrm{C}$ for 1 week.

Under anaerobic conditions, the FIGB culture mainly consisted of Acidithiobacillus ferrooxidans, Sulfobacillus $(S b$.) thermosulfidooxidans and the archaeon Ferroplasma $(F$.) acidiphilum, with the first one dominating (67\%-90.6\%) in all assays (Fig. 2c). At. ferrooxidans is the most widely studied biomining model organism and its ability to reduce iron(III) coupled to sulfur oxidation anaerobically has potential impact in deep in situ biomining or heap bioleaching (e.g. consumption of iron(III) ions in anaerobic/microaerobic zones).

Cells of $F$. acidiphilum accounted for $8.3 \%$ of the community when grown on elemental sulfur under anaerobic conditions. However, the cell proportion decreased to $2.4 \%$ when the pressure increased to 100 bar (Fig. 2c). The presence of $F$. acidiphilum in all tested conditions and its substantial abundance (33\%) at 100 bar in the culture with PT plus SS indicates its potential impact on bioleaching of SS materials under anaerobic conditions. The abundance of $S b$. thermosulfidooxidans increased from $3.8 \%$ at 1 bar to $7.0 \%$ at 100 bar. However, cells were hardly detected in the culture grown on PT.

Table 1 summarizes the data for pressure effects on growth and iron(III) reduction by the enrichment culture TK65. When the pressure increased from 1 bar to 100 bar, cell growth was inhibited by 27 up to $39 \%$ as indicated by direct cell counts and qPCR data. Accordingly, cells 
showed 24\% reduced iron(III) reduction activity at 100 bar. The TK65 culture was mainly identified as $T$. acidophilum and $A$. brierleyi at the end of the assays. Both species are able to gain energy anaerobically by sulfur respiration $[11,12]$. The detection of hydrogen sulfide odor at the end of the experiments indicates that sulfur reduction or disproportionation was carried out by the mixed culture of T. acidophilum and A. brierleyi.

Table 1. Pressure effect on growth and iron(III) reduction by culture TK65. Assays with an initial cell number of $\sim 10^{7}$ cells/ $\mathrm{mL}$ in Hungate tubes were cultivated anaerobically at $55^{\circ} \mathrm{C}$ for 4 days.

\begin{tabular}{llll}
\hline & Iron(II) ions $(\mathrm{mM})$ & Cell count $(/ \mathrm{mL})$ & Gene copy number $(/ \mathrm{mL})$ \\
\hline $\mathrm{S}^{0}, 1$ bar & 27 & $1 \times 10^{9}$ & $5 \times 10^{9}$ \\
$\mathrm{~S}^{0}, 100$ bar & 20 & $8 \times 10^{8}$ & $3 \times 10^{9}$ \\
\hline
\end{tabular}

\section{Summary}

The data show that mesophilic and thermophilic acidophiles are able to reduce soluble iron(III) by oxidation of sulfur compounds under anaerobic conditions at 100 bar. However, microbial activity seems to be lower than at atmospheric pressure. Acidophiles contained in iron(III) solution injected into the underground for deep in situ biomining (up to $1 \mathrm{~km}$ deep) may possess significant biological activities i.e. iron(III) reduction and sulfur oxidation. Microbial iron and sulfur metabolism at elevated temperature and pressure has to be further investigated for evaluation of their contribution to in situ deep ore dissolution.

\section{Acknowledgement}

This work was supported by the European Union Horizon 2020 project BIOMOre (Grant agreement \# 642456).

\section{References}

[1] M. Vera, A. Schippers, W. Sand, Progress in bioleaching: fundamentals and mechanisms of bacterial metal sulfide oxidation-part A, Appl. Microbiol. Biotechnol. 97 (2013) 7529-7541.

[2] E. Pakostova, B. M. Grail, D. B. Johnson, Indirect oxidative bioleaching of a polymetallic black schist sulfide ore, Miner. Eng. 106 (2017) 102-107.

[3] D. B. Johnson, Biomining goes underground, Nat. Geosci. 8 (2015) 165-166.

[4] K. Wakeman, H. Auvinen, D. B. Johnson, Microbiological and geochemical dynamics in simulated-heap leaching of a polymetallic sulfide ore, Biotechnol. Bioeng. 101 (2008) 739750 .

[5] K. Nauhaus, A. Boetius, M. Krüger, F. Widdel, In vitro demonstration of anaerobic oxidation of methane coupled to sulphate reduction in sediment from a marine gas hydrate area, Environ. Microbiol. 4 (2002) 296-305.

[6] D. R. Lovley, E. J. Phillips, Rapid assay for microbially reducible ferric iron in aquatic sediments, Appl. Environ. Microbiol. 53 (1987) 1536-1540.

[7] G. Webster, C. J. Newberry, J. C. Fry, A. J. Weightman, Assessment of bacterial community structure in the deep sub-seafloor biosphere by $16 \mathrm{~S}$ rDNA-based techniques: a cautionary tale, J. Microbiol. Methods 55 (2003) 155-164.

[8] S. Hedrich, A.-G. Guézennec, M. Charron, A. Schippers, C. Joulian, Quantitative monitoring of microbial species during bioleaching of a copper concentrate, Front. Microbiol. 7 (2016) 2044. 
[9] K. Takai, K. Horikoshi, Rapid detection and quantification of members of the archaeal community by quantitative PCR using fluorogenic probes, Appl. Environ. Microbiol. 66 (2000) 5066-5072.

[10] M. A. Nadkarni, F. E. Martin, N. A. Jacques, N. Hunter, Determination of bacterial load by real-time PCR using a broad-range (universal) probe and primers set, Microbiology 148 (2002) 257-266.

[11] A. Segerer, T. A. Langworthy, K. O. Stetter, Thermoplasma acidophilum and Thermoplasma volcanium sp. nov. from Solfatara Fields, Syst. Appl. Microbiol. 10 (1988) 161-171.

[12] G. Wheaton, J. Counts, A. Mukherjee, J. Kruh, R. Kelly, The confluence of heavy metal biooxidation and heavy metal resistance: Implications for bioleaching by extreme thermoacidophiles, Minerals 5 (2015) 397-451. 